\title{
«MY VOICE (STUDY)» КАК ПРОГРАММА ДЛЯ ЭВМ - ОНЛАЙН СИМУЛЯТОР ЭЛЕКТРОННОГО ГОЛОСОВАНИЯ НА ВЫБОРАХ: РАЗВИТИЕ НТИ И GАМЕNЕТ
}

(c) 2020 Шушпанов Михаил Константинович

студент 3 курса

МИРЭА - Российский технологический университет, Россия, Москва

(c) 2020 Макаров Андрей Павлович

студент 3 курса

МИРЭА - Российский технологический университет, Россия, Москва

( 2020 Саражинский Никита Сергеевич

студент 3 курса

МИРЭА - Российский технологический университет, Россия, Москва

(c) 2020 Коновалов Николай Николаевич

доцент кафедры прикладного права, кандидат юридических наук, доцент

МИРЭА - Российский технологический университет, Россия, Москва

\section{(c) 2020 Забайкалов Андрей Павлович}

доцент кафедры прикладного права, кандидат юридических наук, доцент

МИРЭА - Российский технологический университет, Россия, Москва

\section{(c) 2020 Щукина Татьяна Владимировна}

доктор юридических наук, доцент, заведующая кафедрой прикладного права МИРЭА - Российский технологический университет, Россия, Москва

Предметом настоящей статьи выступает исследование новых направлений Национальной технологической Инициативы; рассмотрение правового регулирования проблем современной избирательной системы, внедрения электронного голосования. Тема статьи отражает вопросы разработки образовательных продуктов, полученных в процессе проведения междисциплинарных гуманитарных и технических исследований с точки зрения формирования инновационной цифровой инфраструктуры российских университетов. Целью настоящей статьи является представление программы для ЭВM «My Voice (STUDY)» в формате онлайн симулятора электронного голосования на выборах. Методологию данной работы составили сравнительный, формально-юридический, аналитический методы, методы Web-разработки (frontend и backend). Результаты работы - это формулирование особенностей и значения прикладных образовательных электронных технологий для правового просвещения. Область применения результатов работы включает в себя систему публичного управления и образования.

Ключевые слова: избирательная система, национальная технологическая инициатива, электронное голосование, онлайн симулятор

Впервые о Национальной технологической инициативе и роли научно-технологического развития Российской Федерации было указано в Послании Президента РФ В.В.Путина Федеральному Собранию РФ от 4 декабря 2014 года. Основой правового регулирования государственной поддержки НТР является федеральный закон «О науке и государственной научнотехнической политике». Приоритетной целью НTP выступает создание условий по присут-

ствию Российской Федерации в числе 5 ведущих стран мира, осуществляющих научные исследования и разработки в областях, определяемых приоритетами научно-технологического развития Российской Федерации (Основные направления деятельности Правительства РФ на период до 2024 года). Государственная поддержка научно-технологического развития Российской Федерации осуществляется на основании Стратегии научно -технологического развития 
Российской Федерации, утвержденной указом Президента РФ от 1 декабря 2016 г. № 642. Научно-технологическое развитие предполагает реализацию приоритетных направлений развития науки, техники и технологий государственной научно-технической политики, которые позволяют получить результаты и сформировать компетенции, отвечающим на большие вызовы.

В ближайшие 10-15 лет приоритетами НТР следует считать направления, которые позволят получить научные и научно-технические результаты; создать технологии, являющиеся основой инновационного развития для внутреннего рынка продуктов и услуг. Постановлением Правительства РФ от 29 марта 2019 г. № 377 «Об утверждении государственной программы Российской Федерации «Научнотехнологическое развитие Российской Федерации» была утверждена соответствующая государственная программа. Программа является одним из основных механизмов реализации Стратегии НТР и Основных направлений деятельности Правительства Российской Федерации на период до 2024 года.

Одним из направлений Национальной технологической инициативы в настоящее время является GameNet. Это образовательная инициатива, в рамках которой можно как создать проект с нуля, так и продолжить развивать существующий, сделав из него конкурентный рыночный продукт. В данной статье речь пойдет о разработке подобных образовательных продуктов на базе университетских проектных лабораторий (Междисциплинарная проектная лаборатория института экономики и права РТУ МИРЭА «Интеграция и экспорт высшего образования»). По мнению, Бельски Л. «Глобальная задача всех государств - повышение доступности высшего образования во всем мире и университеты могут стать эпицентром реформ образования. С помощью технологий они могут объединять усилия и создать общую обучающую экосистему, а также дополнить свои собственные программы лучшими курсами от других учебных заведений» [1]. Мировой опыт показывает, что университеты играют разнообразную и зачастую ключевую роль в инновационной национальной системе, а также в создании и развитии человеческого потенциала, НИОКР и развитии инноваций [2].

Представленный междисциплинарный проект направлен на формирование цифровой модели накопления навыков голосования у молодых избирателей. Избирательная система Российской Федерации на современном этапе развития характеризуется значительной динамичностью. Практически каждая крупная избирательная компания проходит по принципиально новым нормам. Одной из основных причин данного явления служит недостаточный уровень необходимых знаний и правовой культуры части населения. Для решения указанных проблем необходимо опираться как на теоретические разработки в различных областях науки (право, социология, политология, история и т.д.), так на применение новых цифровых технологий в электоральной сфере [3].

Федеральный закон от 23 мая 2020 г. № 152Ф3 О проведении эксперимента по организации и осуществлению дистанционного электронного голосования в городе федерального значения Москве» установил правовые основы проведения дистанционных способов выяснения волеизъявления граждан. В соответствии с данным правовым актом дистанционное электронное голосование является одним из важных и соответствующих «духу времени» способом решения теоретических и практических проблем, связанным с институтом прямой демократии.

Отказ от необходимости явки избирателя на избирательный участок и предоставление возможности голосования при помощи сети Интернет давно обсуждалось как среди участников электорального процесса, так и среди экспертного сообщества. Однако общей позиции так и не сложилось. Существует и определенная мировая практика в данной сфере, но она также противоречива [3].

Авторы статьи представляют, в данной связи, программу для ЭВМ «My Voice (STUDY)» в формате онлайн симулятора электронного голосования на выборах. Данная программа выступает как один из стартапов реализации нового направления НТИ - GameNet. Описание правовых норм о процедуре электронного голосования в российской избирательной системе в цифровую форму позволило создать актуальный и интересный междисциплинарный образовательный продукт, а именно, программу для ЭВМ под названием «My Voice (STUDY)». Эта прикладная образовательная электронная технология предназначена для правового просвещения студентов и школьников в области избирательного права. Имитатор электронного голосования «My Voice (STUDY)» создан для того, чтобы молодежь по- 
нимала структуру и правила процедуры голосования на выборах в органы власти любого уровня. Платформа электронного голосования разработана в качестве модели для формирования нового опыта голосования у избирателя. Электронный симулятор голосования доступен для широкого тестирования.

Целью создания программы-симулятора явилось необходимость разработки и внедрения в образовательный процесс обучающей платформы для дистанционного голосования со стороны несовершеннолетних граждан. Задачами разработки выступили: а) формирование навыков избирательных прав для молодых людей возрастом от 16 до 18 лет, б) прогнозное увеличение избирательной активности молодежи, в) воспитание патриотического духа среди граждан, не достигших возраста 18 лет, д) продвижение междисциплинарных проектов в области гуманитарных наук и программирования.

Описание программы: «My Voice (STUDY)» уникальное в своем роде цифровое устройство, созданное специально для потенциальных молодых избирателей. Как показывает статистика из СМИ, к сожалению, явка на избирательные участки среди молодежи далеко не максимальная. Это вызвано рядом причин: нежеланием тратить свое личное время в очереди на получение бюллетеня, недоверие к избирательным комиссиям, отсутствие должного уровня патриотического настроя, условия пандемии. Все это обусловило создание альтернативного решения данной проблемы в цифровом формате.
Соавторы данной статьи: Шушпанов Михаил Константинович, Макаров Андрей Павлович, Саражинский Никита Сергеевич являются авторами программы для ЭВM «My Voice (STUDY)». Благодаря «My Voice (STUDY)» можно стать участником обучающего голосования, фактически не выходя из дома. Просветительская миссия данного онлайн симулятора заключается в определенной борьбе человека со временем, и чем больше рутинных функций мы перекладываем на цифровое обеспечение, тем больше высвобождается времени для творческой деятельности, для создания абсолютно новых и комфортных вещей. Это касается и данной программы, она, например, может быстрее подсчитывать голоса граждан, и тем самым способна упростить работу избирательных комиссий любого уровня.

Представляем описание программы для ЭВM «My Voice (STUDY)». Оно выражается в ее блок схеме, представленной на рисунке 1 и части уникального кода. Часть уникального кода программы для ЭВМ «My Voice (STUDY)»:

$<\operatorname{div}$ class $=»$ fon» $>$

$<$ form $>$

$<\operatorname{div}$ class $=»$ hed»>

$<$ a $>$ Избирательный бюллетень $</$ a $>$

$</ \operatorname{div}>$

$<$ table class $=»$ stroka» $>$

$<\operatorname{tr}>$

$<\mathrm{td}>$

$\langle$ nav class $=»$ vib-menu» $>$...

Текстовое описание блок-схемы программы для ЭВM «My Voice (STUDY)», соответственно

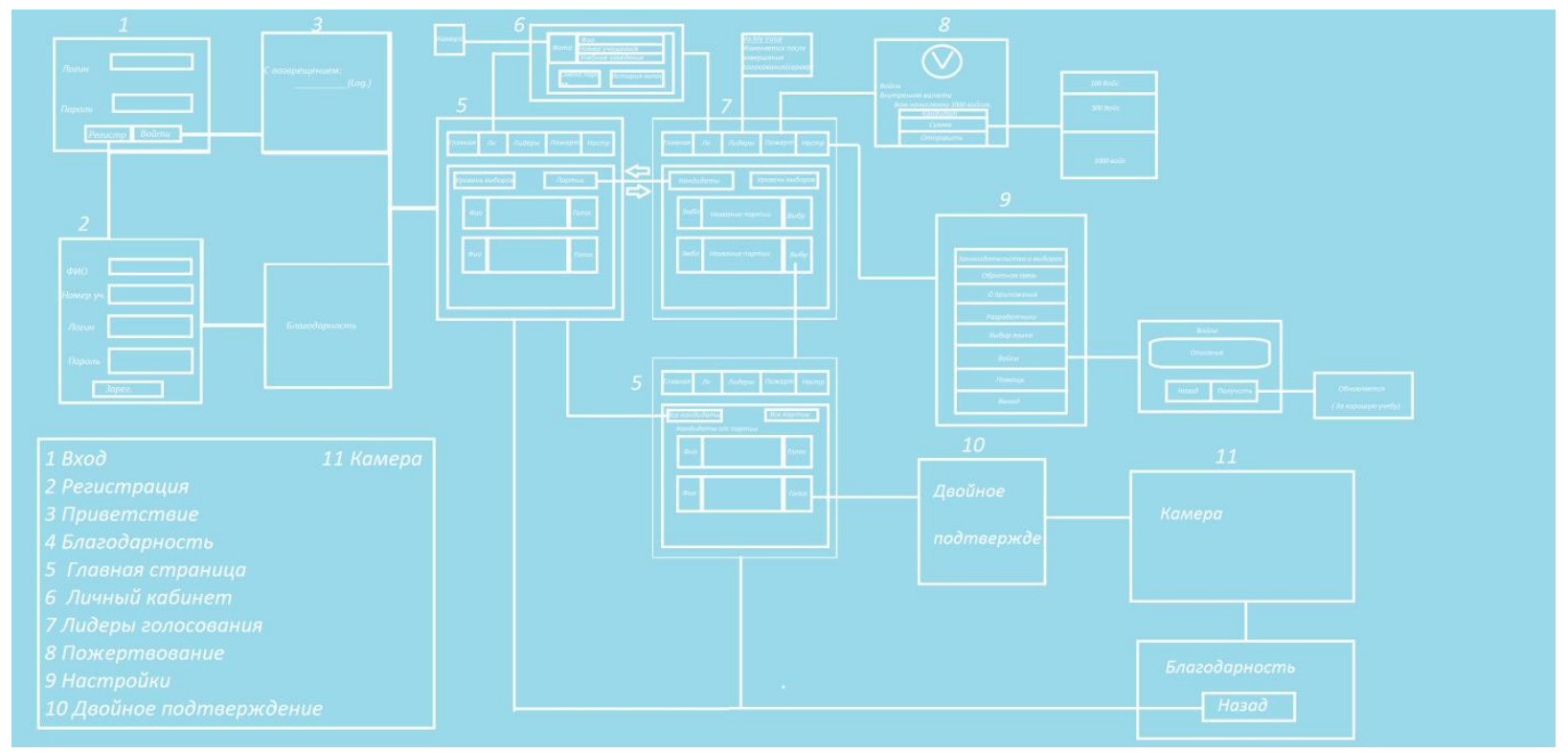

Puc. 1. Блок-схема программы для ЭВМ «My Voice (STUDY)» 
разделы программы:

1) Вход - достаточно привычная для всех форма, где первая страница, как и во многих электронных устройствах, является страница ввода уже зарегистрированных данных.

2) Регистрация - для первичного входа в «My Voice (STUDY)» необходимо обязательно зарегистрироваться; это необходимо для полной ликвидации возможности повторного голосования или накрутки голосов.

3-4) «Приветствие» и «Благодарность» - элементарная благодарность за проявленное терпение в период ввода личных данных для входа.

5) Главная страница - бюллетень, где каждый гражданин может просмотреть кандидатов и выбрать ту кандидатуру, которой наиболее доверяет. Особенность содержания данного раздела программы заключается в наличии целых трех «Главных страниц». Первая из них - общий список кандидатов. Вторая - «Списки партий», где при выборе определенной партии открывается список кандидатов от данной фракции. Третья страница приурочена к локальным выборам в школе или университете (старосты группы или президента класса).

6) Личный кабинет - это страница хранения данных введенных при регистрации. Здесь необходимо введения учета голосов, замена пароля и проверки отданного голоса (был ли отдан за нужного кандидата) и реализуется этот этап голосования соответственно при нажатии кнопок: «Заменить пароль» и «Список ID».

7) Лидеры голосования - страница заключительного результата голосования (до завершения выборов является не кликабельной).

8) Пожертвование - самая интересная часть обучающего устройства, благодаря этому разделу наглядно представляется, как легально можно финансово поддерживать кандидатов. Авторами программы задумана идея внутренней валюты «Войсики». Она абсолютно ничем не поддерживается и является учебной. Получить ее можно за хорошую успеваемость в учебе, а в дальнейшем за ее применение можно получить награду (например, в виде стикеров социальной сети ВК).

9) Настройки - необходимы для регулирования устройства. Данный раздел имеет также страницы: «Законодательство о выборах для изучения своих прав», «Обратная связь для мониторинга недочетов устройства», «Войсики для запроса новых виртуальных денег», «Выход», в случае если гражданин сидит не со своего устройства, и многое другое.

10) Двойное подтверждение - это ликвидация возможности «случайного голосования» методом создания страницы для подтверждения своего голоса.

Обобщим особенности программы для ЭВМ «My Voice (STUDY)»: в ней применяется камера для подтверждения голоса; имеются наличие внутренней валюты для избирателей, а также список ID для проверки своего голоса.

Апробация работы программы была произведена в процессе выборов старост 3 курса юридического факультета. В эксперименте участвовало 212 человек, которые с помощью «My Voice» смогли проголосовать за представленных кандидатов. Полученные результаты голосования полностью совпадали с результатами последующей (добровольной) выборочной проверки итогов выборов.

Подводя итог, можно отметить, что применение цифровых технологий в процессе голосования является реальность современного избирательного процесса, а также перспективным направлением его совершенствования. Отдельно следует отметить, что одной из ключевых проблем применения цифровых технологий в процессе голосования является уровень доверия к ним. Причем речь идет не только о доверии со стороны избирателей, но и доверии со стороны иных участников избирательного процесса. В этом случае новые технологии будут рассматриваться как механизм совершенствования и становление такого доверия находится вне правового поля.

\section{Библиографический список}

1. Belsky, L. (2019), "How technology will change higher education», available at: https://www.vedomosti.ru/ management/articles/2019/12/11/818499-tehn ologii-izmenyat (accessed 11 December 2019)

2. Kolomytseva, O., Pavlovska, A. (2020), «The role of Universities in the National Innovation System», Baltic Journal of Economic Studies, Vol. 6, No. 1, pp. 51-58. 
3. Забайкалов А.П. Применение цифровых технологий в процессе голосования // Государство, общество, бизнес в условиях цифровизации: сборник научных трудов по материалам Всероссийской научнопрактической конференции. Саратов, 2020. С. 36-40. 